\title{
Lorenz Kähler
}

\section{Begriff und Rechtfertigung abdingbaren Rechts}

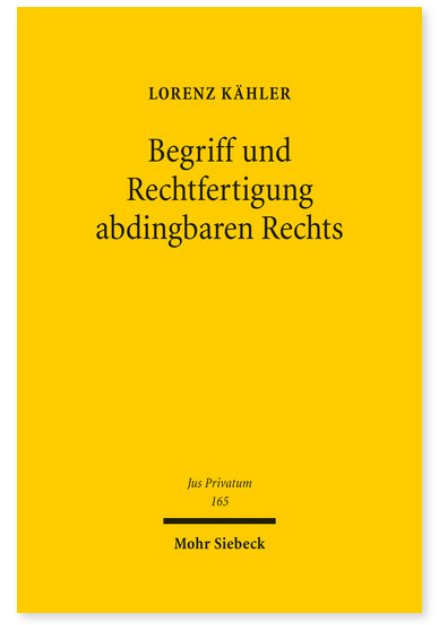

2012. XIV, 480 Seiten. JusPriv 165

ISBN 978-3-16-152096-9

DOI 10.1628/978-3-16-152096-9

eBook PDF $119,00 €$

ISBN 978-3-16-150718-2

Leinen $119,00 €$
Abdingbares Recht tritt in großer Vielfalt und den unterschiedlichsten Formen auf. Das haben die bisherigen Modelle nur ungenügend berücksichtigt. Lorenz Kähler zeigt in seiner Untersuchung, dass sich abdingbares Recht stattdessen als Menge von Normen begreifen lässt, bei denen der jeweilige Adressat die Anwendbarkeit trotz konstanter Geltung ausschließen kann. Aufgrund weitreichender faktischer und rechtlicher Wirkungen bedürfen abdingbare Normen einer Rechtfertigung. Diese beruht nicht unmittelbar auf der Zustimmung der Parteien zum Vertrag, sondern auf einer an diese Zustimmung

anknüpfenden Zurechnung. Daraus ergeben sich zahlreiche Konsequenzen für die Gestaltung und Feststellung abdingbaren Rechts. Etwa lassen sich viele Schutzzwecke mittels abdingbarer Normen erreichen, ohne dass ein zwingender Eingriff in die Vertragsfreiheit erforderlich wäre.

Lorenz Kähler ist Professor für Bürgerliches Recht, Zivilprozessrecht und Rechtsphilosophie an der Universität Bremen.

Jetzt bestellen:

https://mohrsiebeck.com/buch/begriff-und-rechtfertigung-abdingbaren-rechts-9783161520969?no_cache=1 order@mohrsiebeck.com

Telefon: $+49(0) 7071-923-17$

Telefax: $+49(0) 7071-51104$ 